\title{
REGIONAL SOCIAL EXPENDITURES: A COUNTRY OF CONTRASTS ${ }^{1}$ N.Zubarevich
}

Regional consolidated budgets are facing three main trends in 2015, namely marked growth of budget revenues, slower growth of budget expenditures, insignificant growth of debts and enhanced debt profile. The dynamics of the regional consolidated budget revenues in 2015 (according to the data on January-September) has improved amid economic downturn over the dynamics seen in 2013-2014. However, there is a large difference between the regions: some (most) of them have seen their budget revenues decline, whereas others have experienced a substantial growth in the same. The regions and municipalities have seen their debts grow slower than in 20132014 , increasing by merely 5\% in the period between January and earlier in November 2015. Consolidated budget expenditures have increased by merely $4 \%$ due to strengthening the responsibility of the regions for their budget policy. However, analysis of the dynamics of social spending has shown a strong differentiation as to both certain budget lines and regions. The nontransparent regional budgets' Health care spending pattern is an apparent problem.

The dynamics of the regional consolidated budget revenues in JanuarySeptember 2015 improved amid economic downturn over the dynamics seen in the same period of 2013-2014. The dynamics of the regional consolidated budget revenues in January-September 2015 improved amid economic downturn over the dynamics seen in the same period of 2013-2014. Budget revenues in the first three quarters of 2015 increased $8 \%$ from the same period of 2014 due to profit tax revenues (an increase of $14 \%$, or $10 \%$, excluding Sakhalin) and property tax revenues (up 15\%). However, this growth may turn out to be unstable or have an adverse effect on regional budgets, because a considerable growth in profit tax revenues was determined largely by the heavy devaluation of the Russian ruble late in $2014^{2}$. Due to the fact that the profit tax is calculated on the previous periods basis (2014 was more beneficial), many large companies overpaid their profit tax in 2015, and it is budgets that will have to compensate them for the amounts overpaid. The growth in profit tax revenues was determined by higher rates, thereby increasing the tax burden on businesses amid crisis. The overwhelming majority of the regions have seen the principal tax (personal income tax) revenues (up 5\%) and transfers (less than $2 \%$, or $4 \%$, excluding the Republic of Crimea) grow at a considerably slower pace.

The overall dynamics of the regional budgets does not reflect how large the difference between the regions is: budgets revenues have declined in 23 regions, whereas they have increased substantially (by $20-54 \%$ ) in five regions.

1 This paper was originally published in Online Monitoring of Russia's Economic Outlook No.17.

2 Large exporting companies generate incomes denominated in foreign currencies, they accumulated by the end of the year large FX balances on their accounts, on which the profit tax was levied given a difference of exchange. 
The regions and municipalities have seen their debts grow slower than in 2013-2014, increasing by merely $5 \%$ in the period between January and earlier in November 2015. The debts saw the highest growth rates in October 2015 in response to a decline in transfers to the regions and increase in the expenditures commitments. The overall annual dynamics may be worse because debts tend to grow in a period between November and December. The debt profile has improved due to increased federal support in the form of extra budget loans from Russia's Finance

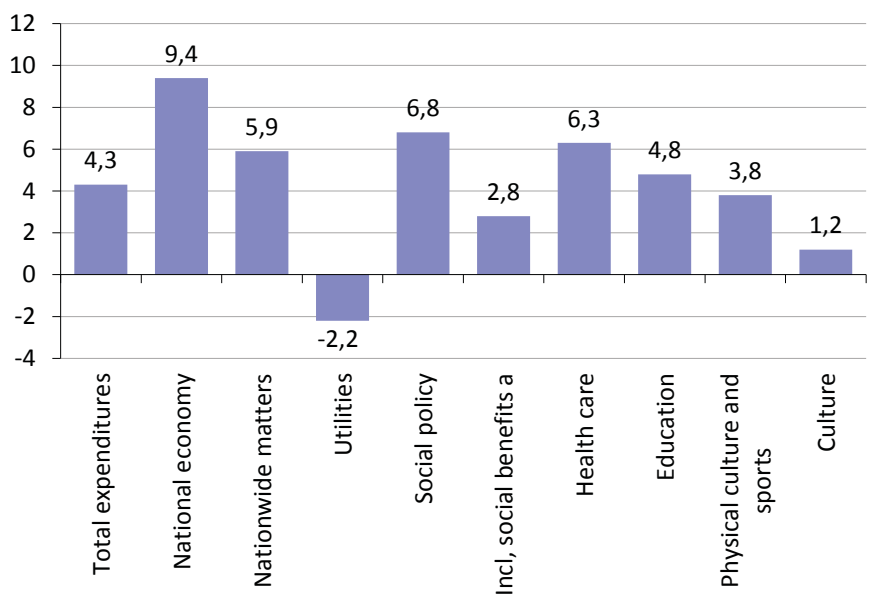

Fig. 1. Regional consolidated budget expenditures in January-September 2015, as a percent change from the same period of 2014

Ministry: the share of commercial

bank loans that are most expensive to service has decreased to $38 \%$ to become equal to the share of budget loans. By contrast, the proportion earlier in 2015 was more of a problem for the regions, 44 and 31\%, respectively. Although Finance Ministry's budget loans allow for easing the burden on the regions, they cannot be a systemic solution for the debt issue.

Consolidated budget expenditures have increased by merely $4 \%$ due to strengthening the responsibility of the regions for their budget policy. What were the priorities in 2015 ? On the face of it, social priorities, which dominated in previous years, have become less apparent in 2015. National economy's expenditures have been growing at a faster pace than during the past two years (Fig. 1).

However, this is due to the policy of Moscow, the single region with a huge budget, which has been responsible for large increase in the national economy expenditures (up 26\%), on transport and road construction. Excluding Moscow, the dynamics of national economy expenditures is one half as high (down 5\%) and comparable with the overall growth in budget expenditures, whereas expenditures have been cut in 33 regions. Utilities expenditures have declined in 50 regions, but the cost-effectiveness has been reached for account of the two federal-status cities, Moscow (a decrease by $8 \%$ ) and St. Petersburg (down 21\%), which totally account for more than two thirds of all the regional budget expenditures on utilities. A substantial growth in utilities expenditures in 15 regions (up 30-230\%) has been determined by having to pay accrued debts to service provides (companies that supply gas, water and electric power) under threat of shutting down supplies. It therefore is not arguable that the social expenditure priority has decreased.

The priority social expenditures have differed in recent years: social protection expenditures saw above-normal growth rates in the 2009-2010 crisis; education and health care expenditures increased in 2012-2013 and culture expenditures in 2014 pursuant to Presidential decreases. According to the data on the three quarters of 2015, the differences in dynamics of specific types of social expenditures have been smoothed out. Social policy and health care expenditures have increased a bit faster with a minimal growth in culture spending. However, this is a general picture. Analysis of the dynamics 
of social expenditures shows large differentiation by both specific line and region.

The growth in education expenditures in the first three quarters of 2015 (5\%) remained at the level seen in 2014 , but the differences in the dynamics as per budget lines became more visible. Pre-primary education expenditures $(13 \%)$ increased most, because the regions must implement a nursery construction program despite a decline in birth rates caused by the specific features of the Russian age pyramid. The growth in basic education financing has been minimal (2\%) due to ongoing streamlining of the school network. Secondary vocational education expenditures, which relates to compensating the regions, have decreased by $0.3 \%$ with a reduction in the number of students and in the network of secondary vocational education institutions.

Health care expenditures are distributed between regional budgets and territorial funds of compulsory medical insurance (TFCMI). TFCMI in 2015 account for the first time for half of the total expenditures (51\%). Including TFCMI, health care expenditures have increased substantially by $11.6 \%$ (Fig. 2).

The structure of regional health care budget expenditures has become the least transparent among other types of social expenditures: the socalled "sundry health care expenditures" account for two thirds, including inter-budgetary transfers, social security and other benefits to individuals, etc. It is these expenditures that are growing faster than budget financing of inpatient and outpatient medical treatment which has been cut by $5-10 \%$ due to streamlining the network of institutions or granting the autonomous nonprofit status to some of such institutions. "Sundry health care expenditures" account for $84 \%$ of total budget expenditures and TFCMI, including primarily insurance compensations to individuals and transfers to municipal budgets. Centralization of health care financing at the regional budget level with transfers to municipalities and growth of financing from TFCMI have made budget statistics on regional health care financing show hardly anything.

Social protection expenditures ("social policy" budget line) increased $6.8 \%$ in the first three quarters of 2015 , but the growth did not catch up with the dynamics seen in 2014 (7.8\% overall annual, excluding the Crimea). Regional social benefits account on average for more than $70 \%$ of social policy expenditures. The dynamics of social protection expenditures as whole and social benefits did not differ in the previous years, but social benefits expenditures in 2015 have been growing at a slower rate (2.8\%). It is the Moscow policy that is primarily responsible for this, cutting social benefits expenditures by $10 \%$. Excluding Moscow, the dynamics of social benefits expenditures is almost the same $(5.5 \%)$ as that of all social protection expenditures.

Cumulative data do not reflect the variety of regional policies with

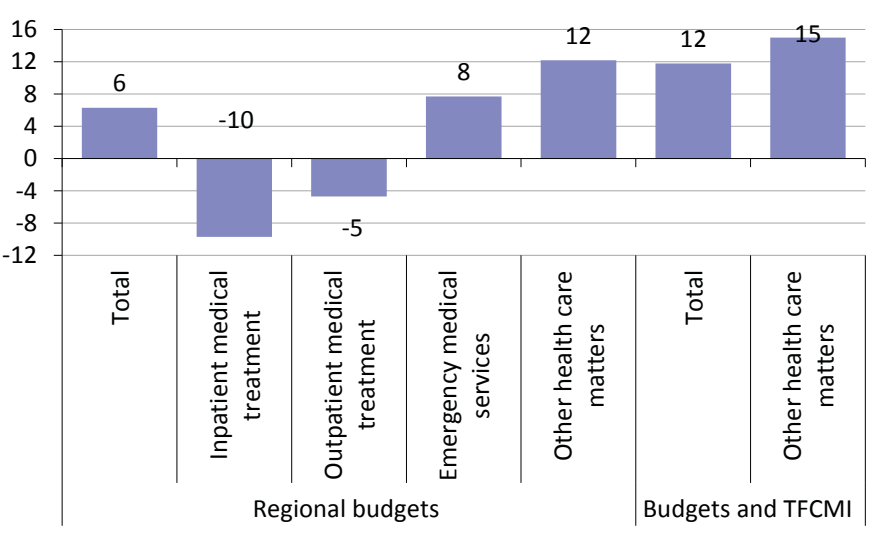

Fig. 2. Regional health care budget expenditures and TFCMI in January-September 2015, as a percent change from the same period of 2014 


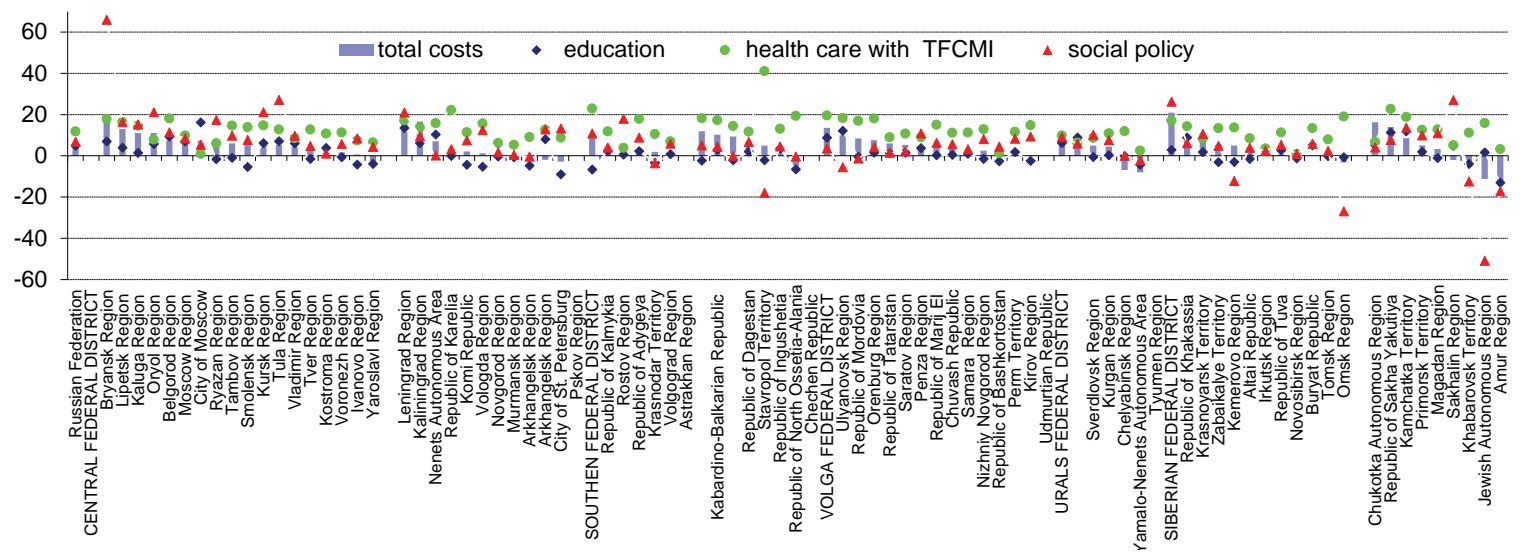

Fig. 3. The dynamics of all expenditures and basic types of social expenditures in January-September 2015, as a percent change from the same period of 2014

regard to social expenditures. As in the previous years, the regional dynamics by key type of social expenditures has been extremely patchy (Fig. 3). Overall, 13 regions (excluding the Crimea) have cut their expenditures, mostly in the Amur Region (down 13\%), the Jewish Autonomous Region (down11\%), the Tyumen Region, the Yamalo-Nenets Autonomous Area and the Chechen Republic (down 7-8\%). This is mostly due to a decline in their budget revenues and, in some cases, the burden of substantial debt owed by a given region.

In 2015 the social expenditure streamlining process has become more widespread in terms of territorial coverage, but only for specific budget expenditure lines. Education is on the top of the list. In 2014 education expenditures as a whole were cut in nine regions, in January-September 2015 in 32 regions. Education expenditures have been cut most in the Amur Region (down 13\%), the Pskov Region (down 9\%), and the Republic of Kalmykia and the Chechen Republic (down 7\%), in which the number of secondary school students has been growing. The biggest growth in education expenditures (up 16\%) has been reported in Moscow due to almost trebled financing of pre-primal education, mostly on the construction of nurseries. High growth rates in education expenditures (11-13\%) have been reported in regions with different degree of fiscal capacity: the Leningrad Region and the Republic of Sakha Yakutiya which are facing favorable situation with their budget, the Republic of Mordovia which has a huge debt, budget deficit and decline in revenues, and the heavily subsidized Kamchatka Territory.

Health care budget expenditures in January-September 2015 were cut in 15 regions, mostly in the Republic of Adygeya (down 12\%), Amur Region (down $10 \%)$, Moscow, the Buryat Republic and the Sverdlovsk Region (down 7-8\%). However, 2014 saw twice as much regions with negative dynamics of budget health care expenditures. It is incorrect to consider budget expenditures alone, TFCMI expenditures should be considered too. They have increased in total in all of the regions, mostly in the Republics of Ingushetia (up 43\%), Karelia, Kalmykiya, Sackha Yakutia, the Chechen Republic, the Altai Republic, the Kamchatka Territory and the Ulyanovsk Region (up 19-23\%). Budget financing of the construction of medical institutions is most often responsible for considerable growth. Moscow, the Perm Territory and the Buryat Republic have seen the slowest growth in expenditures of $1 \%$, the Tyumen Region, $2 \%$. 
Social policy expenditures have been cut only in 10 regions, as in 2014, except that half of them have been cut considerably because of completed social payments to flood victims (Jewish Autonomous Region, Altai Republic, Amur Region, Khabarovsk and Altai Territories). the Republic of Ingushetia have seen most of the cuts (down 18\%) in 2015, which in 2014 experienced inadequately high growth of social benefits expenditures. Substantial growth of social policy expenditures, especially social benefits expenditures, in September 2015 was mostly due to numerous regional election campaigns. The Bryansk Region is on the top of the list (66\%), followed by the Tula, Oryol, Kursk and Leningrad Regions, the Republic of Khakassia (21-27\%) despite that most of the regions have large debts and budget deficit. There is only one superrich Sakhalin region which can afford a substantial growth of $27 \%$ in social policy expenditures. 